\title{
Latent inhibition and schizophrenia
}

\author{
R. E. LUBOW, I. WEINER, A. SCHLOSSBERG, and I. BARUCH \\ Tel-Aviv University, Ramat-Aviv, Israel
}

\begin{abstract}
The phenomenon of latent inhibition (LI) refers to a decrement in associability of a stimulus previously preexposed without being followed by an event of consequence, and it reflects a process of learning not to attend to, or to ignore, irrelevant stimuli. Recently it was demonstrated that amphetamine-treated animals fail to develop LI. This finding has been used to provide additional support for the analogy between the animal amphetamine model of schizophrenia and the human clinical syndrome. The present experiment tested whether schizophrenics would show a similar failure to develop LI. Groups of paranoid schizophrenics, nonparanoid schizophrenics, and normals were either preexposed or not preexposed to a to-be-associated stimulus. For all three populations, learning a new association to the preexposed stimulus was markedly inferior to learning an association to the same stimulus when it was not preexposed. Thus, contrary to expectations, schizophrenics as well as normal subjects demonstrated a strong LI effect. It was suggested that the failure to find an absence of $L I$ in schizophrenics may be due to the fact that these subjects were on a drug regimen that normalizes attentional processes.
\end{abstract}

When a simple stimulus is preexposed repeatedly without being followed by some event of consequence, it subsequently becomes more difficult for this stimulus to enter into a new association than for a stimulus that has not been preexposed. This phenomenon, called latent inhibition (LI) (Lubow, 1973), is considered to be due to a loss of stimulus salience or to a reduction in attention to that stimulus (e.g., Lubow, Weiner, \& Schnur, 1981; Mackintosh, 1975).

Recently, several writers have suggested that latent inhibition might be a useful tool in the study of schizophrenia (Lubow, Weiner, \& Feldon, 1982; Solomon et al., 1981; Solomon \& Staton, 1982; Weiner, Lubow, \& Feldon, 1984). The logic of the argument begins with the well-documented proposition that schizophrenia is characterized, at least in part, by a selective attention disorder (e.g., Garmezy, 1977; McGhie, 1977; Neale \& Cromwell, 1977). The second reason for focusing on the LI paradigm derives from $\mathrm{LI}$ experiments with amphetaminetreated animals. The animal amphetamine model of schizophrenia (e.g., Kokkinidis \& Anisman, 1980; Segal \& Schuckit, 1983) is based on four related findings: (1) amphetamine intoxication in nonschizophrenic humans elicits schizophrenic symptoms that are often clinically indistinguishable from paranoid schizophrenia; (2) amphetamine administration exacerbates existing schizophrenic symptoms and reinduces psychosis in schizophrenics who are in remission; (3) amphetamine administered to animals produces characteristic behavioral disturbances; and (4) antipsychotic drugs used in the treatment of schizophrenia antagonize amphetamine psychosis in humans and amphetamine-induced disturbances in animals.

This study was conducted by I. Baruch in partial fulfillment of the requirements for a master's degee at Tel-Aviv University. Requests for reprints should be sent to R. E. Lubow, Department of Psychology, Tel-Aviv University, Ramat-Aviv, Israel, 69978.
Although the animal amphetamine model has provided valuable information regarding the pharmacological basis and treatment of schizophrenia, it has relied almost exclusively on motor disturbances induced by the drug, particularly stereotyped behavior. Recently, investigators who have recognized this anomaly have used the LI paradigm to study attentional deficits in amphetaminetreated animals. If amphetamine does produce a schizophrenic-like attentional deficit, and if LI depends on intact attentional processes, then animals administered amphetamine should show a disruption of LI. Indeed this finding has received experimental support (Solomon et al., 1981; Solomon \& Staton, 1982; Weiner, Lubow, \& Feldon, 1981; Weiner et al., 1984).

The present study directly investigated, with human subjects, whether there is a disturbance in attentional function, as indexed by disruption of LI, in paranoid and nonparanoid schizophrenics, as compared with normals. To produce LI in adults, the procedure developed by Ginton, Urca, and Lubow (1975) was employed. Ginton et al. found that a stimulus-preexposed group learned a new association much more slowly than did a group not preexposed to the stimulus (i.e., the former group demonstrated the LI effect).

\section{METHOD}

Subjects
Schizophrenic subjects. The volunteer subjects were 39 inpatients
of the Beer-Ya'acov Mental Health Center in Israel. Inclusion of sub-
jects in the study was limited to patients with an unequivocal diagnosis
of schizophrenia, as judged independently by two psychiatrists. All pa-
tients were on medication. Patients were excluded from the study if they
had auditory difficulties or organic brain syndrome or if they had been
treated with electroconvulsive shock during the month preceding the
experiment. (See Table 1 for additional descriptive information.)
The assignment of patients to the paranoid and nonparanoid groups
was carried out in two ways: (1) by formal psychiatric diagnosis ac-
cording to the patient's hospital chart, and (2) by the Maine scale
(Magaro, Abrams, \& Cantrell, 1981). However, since the classifica- 
tion of the patients according to cut-off scores recommended by Magaro et al. (1981) yielded a significant inconsistency with the hospital diagnosis, a different scoring procedure was employed. Patients were classified according to their relative scores on the two subscales. Patients receiving higher scores on the paranoid subscale were classified as paranoids, and patients receiving higher scores on the nonparanoid subscale were classified as nonparanoids. Patients who received the same score on the two subscales were excluded from those analyses that used the Maine scale to differentiate between the two clinical populations. This procedure, used by Brennan and Hemsley (1984), provided greater consistency with the psychiatrists' diagnoses than did that of Magaro et al. (1981).

Since variables such as duration of hospitalization, number of hospitalizations, dosage of medication, and so forth could account for attentional differences, subjects' assignments to the stimulus-preexposed and nonpreexposed groups were based on matching on these variables. However, as can be seen in Table 1, there were large differences between populations on a number of variables (e.g., duration of current hospitalization) and considerable within-group variability.

Matched subjects from the psychiatric-diagnosed groups were randomly assigned to stimulus-preexposed and nonpreexposed groups. At the completion of the study, the data were reanalyzed using the Maine scale diagnostic criteria.

Normal subjects. Forty-eight undergraduate students from Tel-Aviv University participated in this experiment as part of the requirements of an introductory psychology course. For additional information, see Table 1.

\section{Apparatus}

Two lists, consisting of the same 40 pairs of nonsense syllables, were recorded separately, each on one track of a Sony TC-270 stereophonic tape recorder, using a male voice. The lists were repeated five times with no indication as to the termination or restart of each list. The interval between the syllables ranged from 1 to $2 \mathrm{sec}$. Both tracks were rerecorded, with the target stimulus, a white noise produced by a Campden Instrument $\mathbf{5 3 0}$ white noise generator, randomly superimposed $\mathbf{3 0}$ times on one of the recordings. Noise durations, which varied from 0.5 to $2.0 \mathrm{sec}$, averaged $1.25 \mathrm{sec}$. The volume of the syllables was at the level of normal speech, whereas that of the white noise was approximately half the subjective loudness of the verbal material as judged by the experimenters. Thus, two recordings were created, one with the nonsense syllable list alone (L) and one with nonsense syllable list plus target stimulus $(L+S)$. The recordings were presented to the subject through Ando Sa-2 8- $\Omega$ reactance stereo earphones.

\section{Procedure}

Data collection from the normal subjects took place at the laboratories of Tel-Aviv University, and from the clinical groups at the Beer Ya'acov Hospital. The basic procedure was the same for both populations, with one exception. For the clinical groups, the LI session was preceded several days earlier by a session in which the experimenter introduced himself and explained, in general terms, the nature and purpose of the experiment. In the second part of this session, the Maine scale was administered via a semistructured interview.

The experimental procedure was conducted in sound-attenuated rooms. Each subject was seated in front of a table with the tape recorder on it. The experimenter sat beside the subject.

Preexposure phase. The subjects of all groups were instructed to listen carefully to the recording and to count the number of syllables. They were told that they would have to report those numbers at the end of the recording. Subjects were required to monitor the syllables to ensure that they directed their attention to the masking material and not to the target stimulus, a necessary condition for producing LI in adults (Ginton et al., 1975; Lubow, Caspy, \& Schnur, 1982). The preexposed groups were exposed to Recording $\mathrm{L}+\mathrm{S}$, which included the to-beconditioned stimulus together with the nonsense syllables, whereas the nonpreexposed groups were exposed to Recording $\mathrm{L}$, which included only the nonsense syllables. In each of the preexposed groups, half of the subjects had the to-be-conditioned stimulus presented to the right ear, and half to the left ear. Both groups were later tested with the tobe-conditioned stimulus presented to the ear in which it was preexposed. For the nonpreexposed groups, half the subjects were tested with the to-be-conditioned stimulus presented to one ear, and half to the other ear.

Test phase. At the termination of the preexposure phase, each subject was instructed as follows:

We are now starting a new task. During presentation of the recording you will see me raising points on this scoreboard. The adding of the points is dependent on what you will be hearing on the recording. Listen to the recording and watch the score rise. The moment you think you have caught the rule according to which I am raising the points, raise your hand. Repeat this whenever you expect me to raise a point.

In this phase, all groups were exposed to Recording $L+S$. The scoreboard, a $3 \times 7 \mathrm{~cm}$ metal box with two light-emitting diodes, was placed in front of the subject. A point was added to the board at the termination of each noise stimulus.

The session ended either after the subject had raised his/her hand on five consecutive presentations of the noise stimulus or after 30 presentations of the stimulus. The final test score was the number of noise stimuli remaining to the termination of the recording after the subject had raised his/her hand correctly five consecutive times. Subjects who did not reach criterion received a score of 0 .

\section{RESULTS}

Test performance was dichotomous. With the exception of 2 subjects from the normal nonpreexposed group who received intermediate scores, all of the remaining subjects either reached the learning criterion within seven

Table 1

Means and Standard Deviations of Descriptive Data for the Different Groups

\begin{tabular}{|c|c|c|c|c|c|c|c|c|}
\hline & \multirow[b]{2}{*}{ Age } & \multicolumn{2}{|c|}{$\underline{\operatorname{Sex}(n)}$} & \multirow{2}{*}{$\begin{array}{c}\text { Education } \\
\text { (Years) }\end{array}$} & \multirow{2}{*}{$\begin{array}{c}\text { Total } \\
\text { Hospitalization } \\
\text { (Months) } \\
\end{array}$} & \multirow{2}{*}{$\begin{array}{c}\text { No. of } \\
\text { Hospitalizations }\end{array}$} & \multirow{2}{*}{$\begin{array}{c}\text { Current } \\
\text { Hospitalization } \\
\text { (Months) }\end{array}$} & \multirow{2}{*}{$\begin{array}{c}\text { Medication Level } \\
\text { Phenothiazine } \\
\text { (mg/kg) }\end{array}$} \\
\hline & & $\mathbf{M}$ & $\mathbf{F}$ & & & & & \\
\hline \multicolumn{9}{|c|}{ Paranoid Schizophrenics } \\
\hline $\begin{array}{l}\text { Mean } \\
S D\end{array}$ & $\begin{array}{l}45.6 \\
14.0\end{array}$ & 18 & 2 & $\begin{array}{r}10.3 \\
3.4\end{array}$ & $\begin{array}{l}133.5 \\
101.4\end{array}$ & $\begin{array}{l}6.2 \\
4.0\end{array}$ & $\begin{array}{l}66.6 \\
90.5\end{array}$ & $\begin{array}{l}350.0 \\
232.3\end{array}$ \\
\hline \multicolumn{9}{|c|}{ Nonparanoid Schizophrenics } \\
\hline $\begin{array}{l}\text { Mean } \\
S D\end{array}$ & $\begin{array}{l}38.8 \\
17.5\end{array}$ & 12 & 7 & $\begin{array}{l}9.1 \\
4.5\end{array}$ & $\begin{array}{l}93.8 \\
84.8\end{array}$ & $\begin{array}{l}6.8 \\
5.9\end{array}$ & $\begin{array}{l}12.3 \\
16.7\end{array}$ & $\begin{array}{l}237.0 \\
198.5\end{array}$ \\
\hline \multicolumn{9}{|c|}{ Normal Subjects } \\
\hline $\begin{array}{l}\text { Mean } \\
S D\end{array}$ & $\begin{array}{r}23.0 \\
3.7\end{array}$ & 20 & 28 & $\begin{array}{r}13.0 \\
0.0\end{array}$ & & & & \\
\hline
\end{tabular}




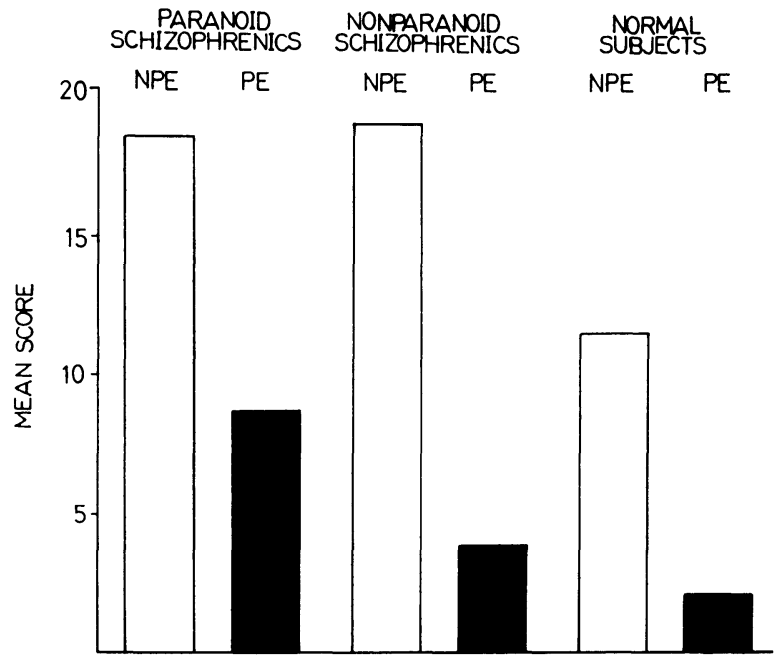

Figure 1. Mean number of trials to reach learning criterion for stimulus-preexposed groups (PE) and nonpreexposed groups (NPE) for three subject populations.

trials or not at all. As a result, the data were analyzed using either chi-square or Fisher exact probability tests. Omitted from these analyses are the 2 subjects mentioned above plus 1 subject from the paranoid schizophrenic stimulus preexposure group who did not complete the test.

Figure 1 displays the mean number of trials to reach the learning criterion for each of the stimulus-preexposed and nonpreexposed groups (including the two intermediate subjects). As can be readily seen, for each of the subject populations, the preexposed group performed more poorly than the nonpreexposed group.

Comparing numbers of normal subjects who learned or did not learn indicates that performance was significantly poorer for the preexposed as compared to the nonpreexposed group $\left[\chi^{2}(1)=7.64, p<.001\right]$; performance was similar for the combined schizophrenic group $\left[\chi^{2}(1)=\right.$ $8.85, p<.001]$. Comparisons within the nonparanoid and paranoid schizophrenic groups indicate that for both groups the difference between preexposure and nonpreexposure was reliable $(p<.05$ in both cases, Fisher's exact probability test). Thus, LI occurred not only in the normal group but also in schizophrenic subjects, both paranoid and nonparanoid. In fact, the data suggest that there might be a potentiation of the LI effect in the schizophrenic subjects. However, this is difficult to evaluate because the normal group performed more poorly than did the combined schizophrenic groups in both the preexposed and nonpreexposed conditions $\left[\chi^{2}(1)=3.4\right.$, $p<.05$, and $\chi^{2}(1)=4.53, p<.05$, respectively].

The data were reclassified according to the Maine scale and reanalyzed. The same overall pattern as that described above was obtained. Normal, paranoid, and nonparanoid subjects all showed significant LI.

\section{DISCUSSION}

As in Ginton et al.'s (1975) study, normal subjects receiving a series of stimulus preexposures failed to learn a new association to that stimu- lus as compared with a nonpreexposed group. Contrary to our expectations, which were based on results obtained with amphetamine-treated animals, schizophrenic subjects, both paranoid and nonparanoid, also learned to ignore or not to attend to the noise stimulus, as reflected in their subsequent failure to learn the association between the stimulus and the change in the value of the counter. There are two possible explanations for the latter outcome. First, the LI phenomenon, although successful in reflecting attentional deficits in animals, may not be suitable for tapping such deficits in humans. This dissociation may be related to the fact that the procedures used for obtaining $L I$ in animals differ considerably from those used with humans; that is, the procedure with humans requires masking (Lubow, Caspy, \& Schnur, 1982). Indeed, the LI procedure, as employed with human subjects, resembles the dichotic listening task in that it includes two types of information, only to one of which the subjects are explicitly directed to attend. In general, these experiments (e.g., Korboot \& Damiani, 1976; Payne, Hochberg, \& Hawks, 1970; Pogue-Geile \& Oltmanns, 1980; Schneider, 1976) indicate that schizophrenics can attend successfully to competing messages. Those deficits that are found in shadowing performance when task requirements are made more difficult (e.g., fast presentation rate, explicit instructions to attend to the irrelevant message, delayed recall of the shadowed material) do not appear to be due to simple selective attention or filtering deficits (e.g., Payne et al., 1970; Pogue-Geile \& Oltmanns, 1980; Schneider, 1976). In view of the above, it may not be surprising that schizophrenics in the present study exhibited the LI effect.

The second explanation derives from the fact that the patients in the present study were under medication. Many studies have shown that the amelioration of schizophrenic symptoms treated with antipsychotic drugs is related to the normalization of the attentional deficits (e.g., Braff \& Saccuzzo, 1982; Kornetsky, 1972; Maloney, Sloane, Whipple, Razani, \& Eaton, 1976; Oltmanns, Ohayon, \& Neale, 1978; Rappaport, Silverman, Hopkins, \& Hall, 1971; Spohn, Lacoursiere, Thompson, \& Coyne, 1977). In line with this evidence, and directly relevant to the present results, are the findings that amphetamine-treated animals that receive chlorpromazine (Solomon et al., 1981) or haloperidol (Weiner \& Feldon, 1987) show a normal LI effect. Moreover, we have recently shown that haloperidol, administered on its own, dramatically facilitates LI in animals (Weiner \& Feldon, 1987; Weiner, Feldon, \& Katz, 1987). These results suggest that neuroleptics may enhance attentional processes and support the possibility that the presence of LI in schizophrenics may be due to antipsychotic medication. If this supposition is correct, it would strengthen even further the analogy between the animal-amphetamine model and the clinical syndrome.

\section{REFERENCES}

BrafF, D. L., \& SACcuzzo, D. P. (1982). Effect of antipsychotic medication on speed of information processing in schizophrenic patients. American Journal of Psychiatry, 139, 1127-1130.

BRENNAN, J. H., \& HeMsLEY, D. R. (1984). Illusory correlation in paranoid and nonparanoid schizophrenia. British Journal of Clinical Psychology, 23, 225-226.

GARMEZY, N. (1977). The psychology and psychopathology of attention. Schizophrenia Bulletin, 3, 360-368.

Ginton, A., URCA, G., \& LuBow, R. E. (1975). The effects of preexposure to a non-attended stimulus on subsequent learning: Latent inhibition in adults. Bulletin of the Psychonomic Society, 5, 5-8.

KoKKINIDIS, L.., \& ANISMAN, H. (1980). Amphetamine models of paranoid schizophrenia: An overview and elaboration of animal experimentation. Psychological Bulletin, 3, 551-579.

Korboot, P. J., \& Damiani, N. (1976). Auditory processing speed and signal detection in schizophrenia. Journal of Abnormal Psychology, 85, 287-295.

KoRNETSKY, C. (1972). The use of simple test of attention as a measure of drug effects in schizophrenic patients. Psychopharmacologia, 24, 99-106.

LuBow, R. E. (1973). Latent inhibition. Psychological Bulletin, 79, 390-407.

LuBOw, R. E., CASPY, T., \& SCHNUR, P. (1982). Latent inhibition and learned helplessness in children: Similarities and differences. Journal of Experimental Child Psychology, 34, 231-256. 
Lubow, R. E., Weiner, I., \& Feldon, J. (1982). An animal model of attention. In M. Y. Spiegelstein \& A. Levy (Eds.), Behavioral models and the analysis of drug action. Amsterdam: Elsevier.

Lubow, R. E., WeIner, I., \& SChNuR, P. (1981). Conditioned attention theory. In G. H. Bower (Ed.), The psychology of learning and motivation (Vol. 15). New York: Academic Press.

Mackintosh, N. J. (1975). A theory of attention: Variations in the associability of stimuli with reinforcement. Psychological Review, 82, 276-298.

Magaro, P., Abrams, L., \& Cantrell, P. (1981). The Maine scale of paranoid and nonparanoid schizophrenia: Reliability and validity. Journal of Consulting \& Clinical Psychology, 49, 438-447.

Maloney, M. P., Sloane, R. B., Whipple, K., Razani, J., \& EaTON, E. M. (1976). Auditory attention in process and reactive schizophrenics. Biological Psychiatry, 11, 325-335.

MCGHIE, A. (1977). Attention and perception in schizophrenia. In B. A. Maher (Ed.), Progress in experimental personality research (Vol. 5). New York: Academic Press.

Neale, J. M., C Cromwell, R. L. (1977). Attention and schizophrenia. In B. A. Maher (Ed.), Progress in experimental personality research (Vol. 5). New York: Academic Press.

Oltmanns, T. F., Ohayon, J., \& Neale, J. M. (1978). The effects of antipsychotic medication and diagnostic criteria on distractibility in schizophrenia. Journal of Psychiatric Research, 14, 81-91.

Payne, R. W., Hochberg, A. C., \& HaWks, D. V. (1970). Dichotic stimulation as a method of assessing disorder of attention in overinclusive schizophrenic patients. Journal of Abnormal Psychology, 76, 185-193.

Pogue-Geile, M. F., \& Oltmanns, T. F. (1980). Sentence perception and distractability in schizophrenic, manic, and depressed patients. Journal of Abnormal Psychology, 89, 115-124.

RAPPAPORT, M., Silverman, J., Hopkins, H. K., \& Hall, K. (1971). Phenothiazine effects on auditory signal detection in paranoid and nonparanoid schizophrenics. Science, 174, 723-725.
SCHNEIDER, S. J. (1976). Selective attention in schizophrenia. Journal of Abnormal Psychology, 85, 167-173.

SEGAL, D. S., \& SCHUCKIT, M. A. (1983). Animal models of stimulantinduced psychosis. In I. Creese (Ed.), Stimulants: Neurochemical, behavioral, and clinical perspectives. New York: Raven Press.

Solomon, P. R., Crider, A., Winkelman, J. W., Turi, A., Kamer, R. M., \& KAPLAN, L. J. (1981). Disrupted latent inhibition in the rat with chronic amphetamine or haloperidol-induced supersensitivity: Relationship to schizophrenic attention disorder. Biological Psychiatry, 16, 519-537.

Solomon, P. R., \& Staton, D. M. (1982). Differential effects of micro injections of d-amphetamine into the nucleus accumbens or the caudate putamen on the rat's ability to ignore an irrelevant stimulus. Biological Psychiatry, 17, 743-756.

Spohn, H. E., Lacoursiere, R. B., Thompson, K., \& Coyne, L. (1977). Phemothiazine effects on psychological and psychophysiological dysfunction in chronic schizophrenics. Archives of General Psychiatry, 34, 633-644.

WeINER, I., \&ELDON, J. (1987). [Haloperidol reverses amphetamineinduced abolition of latent inhibition]. Unpublished raw data.

WeINER, I., \& FeLDON, J. (1987). Facilitation of latent inhibition by haloperidol in rats. Psychopharmacology, 91, 248-253.

Weiner, I., Feldon, J., \& KaTZ, Y. (1987). Facilitation of the expression but not the acquisition of latent inhibition by haloperidol in rats. Pharmacology, Biochemistry \& Behavior, 26, 241-246.

Weiner, I., Lubow, R. E., \& FeLDON, J. (1981). Chronic amphetamine and latent inhibition. Behavioral Brain Research, 2, 285-286.

Weiner, I., LuBow, R. E., \& Feldon, J. (1984). Abolition of the expression but not the acquisition of latent inhibition by chronic amphetamine in rats. Psychopharmacology, 83, 194-199.

(Manuscript received for publication March 26, 1987.) 